\title{
Measuring Diversity in Plant Communities with Mosaic Spatial Patterns: Danish Coastal Dunes
}

\author{
Christian Damgaard ${ }^{*}$, , Bettina Nygaard $^{2}$, Knud Erik Nielsen $^{1}$ and Rasmus Ejrnæs ${ }^{2}$ \\ ${ }^{I}$ Department of Terrestrial Ecology, NERI, Aarhus University, Vejlsøvej 25, 8600 Silkeborg, Denmark \\ ${ }^{2}$ Department of Wildlife Ecology and Biodiversity, NERI, Aarhus University, Grenåvej 14, 8410 Rønde, Denmark
}

\begin{abstract}
Hierarchical pin-point data from 5316 plots from 73 Danish coastal dune sites were analysed in order to describe the species diversity in dune plant communities on a regional scale. Due to the mosaic spatial pattern of the dune communities, it was decided to describe the spatial structure of each plant species in each community using a vegetation type conditioned approach, where the hierarchical pin-point data were fitted to a zero-inflated generalised binomial distribution. Furthermore, summary statistics of the Lorenz curve of the regional estimates of species abundance are suggested in order to describe inequality of species abundance and to test for a possible log-normal species abundance distribution. The mean plant cover and the degree of spatial aggregation were estimated for all species found in six dune communities. Most plant species had a significant aggregated spatial distribution, and there was a significant positive correlation between the mean plant cover and the degree of aggregation. Species abundance did not depart from a lognormal species abundance distribution in any of the investigated dune community types. A vegetation type conditioned approach was found to be appropriate for analysing vegetation data of mosaic vegetation at a regional scale, and it is expected that the introduced method of measuring the direction of the deviation from a log-normal distribution will be important for interpreting the underlying cause of observed departures from log-normally distributed abundance curves.
\end{abstract}

Keywords: Diversity, inequality, log-normal distribution, lorenz curve, pin-point, plant cover.

\section{INTRODUCTION}

In Northern Europe, loss of natural dynamics due to coastal protection, acidification and eutrophication, ground water extraction and changes in land use causes accelerated fixation of the sand and vegetation succession in coastal dunes. During the last decades, there has been a loss of open and species-rich vegetation and a widespread invasion by tall grasses and bushes (Veer and Kooijman, 1997). The most apparent threat to the Danish coastal dune heaths is a massive invasion of exotic trees and bushes like Pinus mugo and Rosa rugosa, but also native shrubs and trees are spreading in the dunes - e.g. Salix cinerea, Hippophaë rhamnoides and Quercus robur. In order to mitigate the current decline of biodiversity, it is necessary to understand the complicated physical and ecological processes in coastal dunes, and a critical step in such an understanding is the establishment of a detailed description of the species diversity at different coastal dune habitats.

The vegetation in North-European coastal dunes is mainly controlled by the movement of the sand and, generally, the dune vegetation may be classified along a disturbance gradient (Warming, 1909, Willis, 1989). However, the wind-controlled topography of the coastal dunes also creates a number of dry and moist areas with differently oriented slopes which have a large influence on the vege-

*Address correspondence to this author at the Department of Terrestrial Ecology, NERI, Aarhus University, Vejlsøvej 25, 8600 Silkeborg, Denmark; Tel: +45-89201598; Fax: +45-89201414; E-mail: cfd@dmu.dk tation, and the coastal dune vegetation will typically be a mosaic of different plant communities. Closest to the coast, where the disturbance due to wind is highest, the white dunes predominate, while grey dunes with herbaceous vegetation occur in fixed and stabilised dunes where the sand is leached and rather acidic. Decalcified fixed dune heaths are less frequently disturbed and colonised by a more closed vegetation carpet of dwarf shrubs (Empetrum nigrum, Calluna vulgaris), lichens and mosses. The last main dune habitat type included in this study is humid dune slacks, which consists of various humid depressions in the coastal dune systems.

A significant proportion of the North-European dunes are situated in Denmark, primarily along the west coast (Doody, 1994), and Denmark hosts $20 \%$ of the total area of dune habitats in Northern Europe and more than $80 \%$ of the area with decalcified fixed dune heaths with Empetrum nigrum (EUNIS, 2008).

The aim of this paper is to describe the observed biodiversity in coastal dune communities and, more generally, to suggest a novel method for characterising species diversity that is appropriate for habitats with several plant communities occurring in a mosaic pattern. Instead of relying on an a priori determined spatial sampling method, the strategy suggested here is to condition the analysis on the vegetation type, i.e. first to identify the different plant community types in the various habitats, then to classify a number of small plots by their community type, and finally to analyse the plots belonging to the same community type on a regional scale. 
The species diversity at the regional scale will be sampled in many relatively small plots that belong to the same community type and the distribution of each species will be summarized by the three parameters in the zeroinflated generalised binomial distribution (Damgaard, 2009). For each species that was observed in a specific plant community, the spatial arrangement of the species was characterised by a parameter that measured the probability of observing the species at a site, and conditioned that a species was present at a site, two parameters that measure the expected mean cover and the spatial aggregation of the species, respectively. Using such a conditioned approach, the observed spatial structure of a specific plant community will be independent of the specific spatial arrangement of the different plant communities that form the mosaic vegetation, and thus independent of local physical and chemical gradients. We expect that the reporting of these three parameters of the zero-inflated generalised binomial distribution, which have been shown to give a good description of hierarchical pin-point cover data (Damgaard, 2009), will enable a more fruitful comparison between other North-European coastal mosaic dune communities and the investigated Danish coastal dune communities.

The Lorenz curve is used for describing the inequality of species abundance and the shape of the species abundance curve of the different communities (Wittebolle et al., 2009). The reason for using the Lorenz curve for summarising inequalities in species cover distributions is twofold: i) the properties of the Lorenz curve and the associated Gini statistic are well known and have become the standard procedure for measuring inequalities in studies of the size distribution in plant populations as well as in economics (Weiner and Solbrig, 1984, Sen, 1973), ii) the shape of the Lorenz curve is mathematically closely linked to the lognormal distribution (Damgaard and Weiner, 2000), which has been considered a suitable null-model of species abundance curves (Preston, 1948, Sugihara, 1980, Magurran, 2004, McGill and al., 2007), and has been suggested as an indication of a relatively undisturbed ecosystem in the sense that if the species abundance curve is log-normally distributed, then the plant community may be assumed to be selforganized and little disturbed by exceptional external factors such as pollution (Halloy and Barratt, 2007, Gray, 1981, Kevan et al., 1997). Furthermore, it has recently been suggested that if communities are highly uneven, or if there is extreme dominance by one or a few species, then the functioning of the ecosystem is less resistant to environmental stress (Wittebolle et al., 2009).

The use of the Lorenz curve allows a classification of how the observed species abundance curve deviates from log-normal, i.e., is the deviation due to relatively many rare species or few very abundant species (Damgaard and Weiner, 2000). Thus, the use of the Lorenz curve allows a direct link between the shape of the species abundance curve, the measurement of inequality, a suitable null model, and a classification of how the species abundance curve deviates from the null model, and this direct link is an important advantage compared to other measures of species evenness which are unrelated to suitable null models of species abundance.

\section{MATERIALS AND METHODS}

\section{Site Description and Sampling Methods}

The monitoring of the conservation status of Danish dunes was conducted in coastal dunes where one or more of three habitats in the Annex 1 of the Habitats Directive (EU, 1992) were present: 1) Fixed coastal dunes with herbaceous vegetation ('grey dunes') (type 2130), 2) Decalcified fixed dunes with Empetrum nigrum (type 2140) and 3) Humid dune slacks (type 2190). The Danish monitoring programme encompasses 73 coastal dune sites (Fig. 1) with 20-60 randomly placed plots, where species abundances of higher plants is measured by the pin-point method in frames of 50 $\mathrm{cm}$ x $50 \mathrm{~cm}$ with 16-grid point (Kent and Coker, 1992, Svendsen et al., 2005). In 2004 to 2006, a total of 5316 coastal dune plots were sampled, and the habitat type of each plot was determined by the use of national field keys (Fredshavn, 2004) based on the Interpretation Manual (European Commission 2007). For more details on the sampling procedure see http://www.dmu.dk/International/ Monitoring/NOVANA/.

\section{Ordination and Classification of Habitat Types}

An initial clustering and classification of the dune plots was conducted in order to divide plots into floristically welldefined plant communities for the subsequent statistical analyses. We considered it inappropriate to work directly on the field determination of the habitat types, as these are defined geomorphologically rather than ecologically (European_Commission, 2007). The dune habitats contain long and important ecological gradients in moisture and $\mathrm{pH}$ as well as disturbance and therefore they hold a considerable floristic variation. Herbaceous dunes include both green and grey dunes (pH-gradient), dune heaths include both dry and wet dunes (moisture gradient) and dune slacks include both acidic mires and alkaline fens (pH-gradient). Furthermore, the field classification involves an element of subjective decision that we have decided to replace with a statistical classification merely based on the floristic composition, but supervised by the field determination of the habitat type.

First, we performed separate TWINSPAN classifications in order to divide the plots into two major groups within each of the three habitat types. Second, the six dune classes were used as a priori classes in a supervised classification model using ordination scores from DCA-ordination (of 5316 plots and 711 species) to predict class membership (Ejrnæs et al. 2004). Finally, we performed an Indicator Species Analysis (Dufrene and Legendre, 1997) in order to facilitate our interpretation of the model predictions (The details of the classification method is further explained in Damgaard et al., 2008).

\section{Plant Cover}

Two important characteristics of the distribution of plant species has to be taken into account when describing the distribution of cover: i) plant species do not occur everywhere possible and the data will, consequently, be zeroinflated, i.e. in some sites a specific plant species may be totally absent due to random extinction events and/or limited 


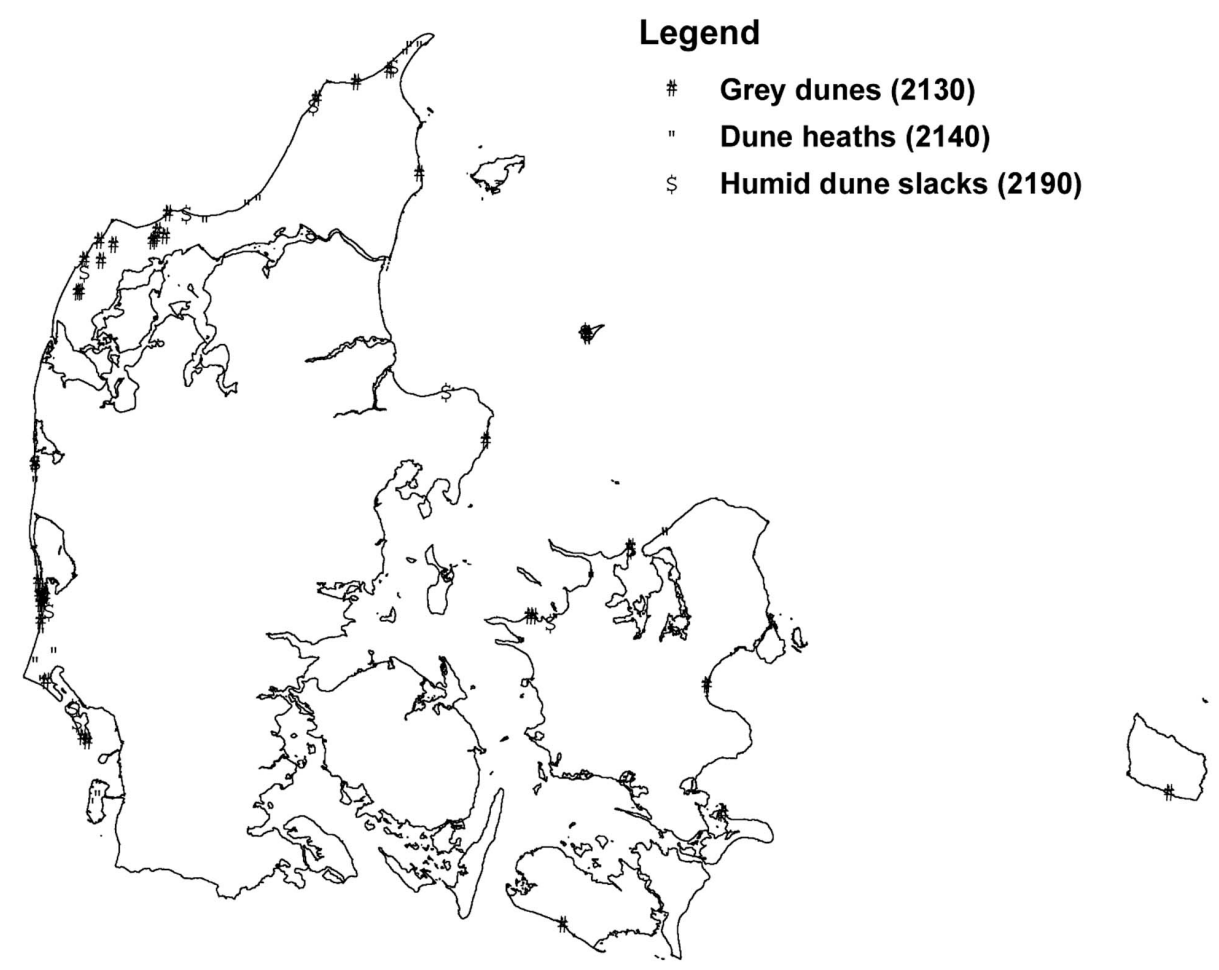

Fig. (1). Map of Denmark with the 73 costal dune sites where the data in the present study was sampled. The legend shows the most abundant habitat type for each site.

possibility of the plant to colonise the habitat (Rees et al., 2001, MacArthur and Wilson, 1967, Cordonnier et al., 2006, Leibold et al., 2004), ii). If a plant species is present at the sites, the abundance of different plant species generally displays aggregated spatial patterns within the site due to e.g. the size of the plant, clonal growth, and limited seed dispersal, and plant cover data will typically be over-dispersed relative to random expectations (Herben et al., 2000, Stoll and Weiner, 2000, Pacala and Levin, 1997). Consequently, the mean and spatial variance of the plant cover of each plant species at the regional scale (here defined as all Danish coastal dunes) were estimated for each dune community type using a zero-inflated generalised binomial distribution,

$$
f_{Y}(y ; n, p, q, \delta)=\left\{\begin{array}{cc}
p+(1-p) \frac{\phi\left(\frac{(1-q)(1-\delta)}{\delta}, n\right)}{\phi\left(\frac{1}{\delta}-1, n\right)} & y=0 \\
(1-p)\left(\begin{array}{l}
n \\
y
\end{array}\right) \frac{\phi\left(q\left(\frac{1}{\delta}-1\right), y\right) \phi\left(\frac{(1-q)(1-\delta)}{\delta}, n-y\right)}{\phi\left(\frac{1}{\delta}-1, n\right)} & 0<y \leq n
\end{array}\right.
$$

where the parameters are explained in Table $\mathbf{1}$, and $\varphi$ is the Pochhammer function, $\phi(x, n)=\Gamma(x+n) / \Gamma(x)=x(x+1) \ldots(x+n-1)$ (Damgaard, 2009, Damgaard et al., 2008, Damgaard, 2008). The mean is independent of $\delta$ and, thus, equal to the mean of the uncorrelated zero-inflated binomial distribution; $E(Y)=(1-p) n q$. The variance, however, does depend on the intra-class correlation parameter $\delta$; $\operatorname{Var}(Y)=(1-p) n q(1-q(1-p n+\delta(n-1))+\delta(n-1))$, and, more specifically, if $\delta>0$, then the variance of the number of hits will be augmented relative to the binomial distribution.

Table 1. The Parameters in the Zero-Inflated Generalised Binomial Distribution

\begin{tabular}{|c|c|}
\hline Parameter & Description \\
\hline$y$ & $\begin{array}{c}\text { Number of times a specific plant species is hit in a pin } \\
\text { point frame. }\end{array}$ \\
\hline$n$ & Number of grid points in the grid point frame $(n=16)$. \\
\hline$p$ & $\begin{array}{l}\text { Probability that the plant species is absent from a site. The } \\
\text { parameter is estimated as: number of sampled plots from a } \\
\text { specific community type from stations where the species } \\
\text { has not been found/ number of sampled plots from a } \\
\text { specific community type }\end{array}$ \\
\hline$q$ & $\begin{array}{l}\text { Expected plant cover in a specific community type if the } \\
\text { species is found at the site }\end{array}$ \\
\hline$\delta$ & $\begin{array}{l}\text { Intra-plot correlation of pin-point hits. For plant species } \\
\text { with an average large cover or plant species that tend to be } \\
\text { spatially aggregated, e.g. clonal plants, the number of hits } \\
\text { within a pin-point frame are positively correlated. The } \\
\text { hypothesis of no correlation (binomial distributed hits) } \\
\text { may be tested in a likelihood ratio test by setting } \delta=0 \text {. }\end{array}$ \\
\hline
\end{tabular}

The hierarchically structured pin-point plant cover data was fitted to the zero-inflated generalised binomial distribution, and the adequacy of the fitted model was assessed by 
visual inspection of plots of the observed and expected plant cover distributions from plant cover data where the species was positively known to be present (Damgaard, 2009).

Since the probability of absence is smaller or equal to the probability of not being found, the estimates of the probability that a plant species is absent from a site $(p)$ are weighted by the number of plots investigated at the site. This also ensures that the estimate of the mean plant cover in the zero-inflated generalised binomial distribution is comparable to the empirical mean of the plant cover data. For dominant species, the probability of detection is relatively high even when the intra-plot correlation is high. For example, if $q>$ $0.05, d=0.7$, and 40 plots are investigated, then the probability of detection is larger than 0.99 .

\section{Diversity Indices}

In order to summarise the distribution of the plant cover of the different plant species and to characterize the vegetation, it is common to calculate different indices of biodiversity (Magurran, 2004, Jost, 2007). The different indices summarise different aspects of biodiversity, and here we use the number of species as well as the Shannon and Simpson diversity measures. These measures are related by:

${ }^{k} D=\left(\sum_{i=1}^{S} p_{i}^{k}\right)^{\frac{1}{1-k}}$

where $S$ is the number of species, $p_{i}$ the estimated mean plant cover of species $i$, and $k$ is the order of the diversity index (Béla, 1995, Jost, 2007). That is, if $k=0$ then $D=S$ ), if $k \rightarrow 1$, the expression is equal to the exponential form of the
Shannon index $(\operatorname{Exp}(H))$, and if $k=2$, the expression is equal to the Simpson index $(1 / H)$. Consequently, if the order $k$ is increased, then the weight of the dominant species is increased in the indices (Jost, 2007).

The inequality in the species cover distribution was characterised by the Lorenz curves, where the cumulative proportion of species (after they are ordered according to mean cover) is plotted against the corresponding proportion of cumulative total cover (Lorenz, 1905). The shape of the Lorenz curve is summarised by the Gini coefficient, which is a direct measure of inequality (Gini, 1912, Dagum, 1980), and the Lorenz Asymmetry Coefficient (LAC) (Damgaard and Weiner, 2000), which is a measure of the departure from the log-normal distribution. Statistical inferences on the observed LAC may be obtained using the bootstrap technique, and if LAC is not significantly different from one, the species cover distribution may be assumed to be lognormal (Damgaard and Weiner, 2000). If LAC $<1$, the inequality in the distribution of plant cover is primarily caused by relatively many rare species, and if LAC $>1$, the inequality in the distribution of plant cover is primarily caused by a few, very abundant, species (Damgaard and Weiner, 2000).

\section{RESULTS}

\section{A Priori Classification of Dune Plots}

The position of the 5316 dune plots along the first two ordination axes of the DCA analysis is shown in Fig. (2). The first axis could be interpreted as a moisture gradient, ranging from very dry grey dunes with Corynephorus

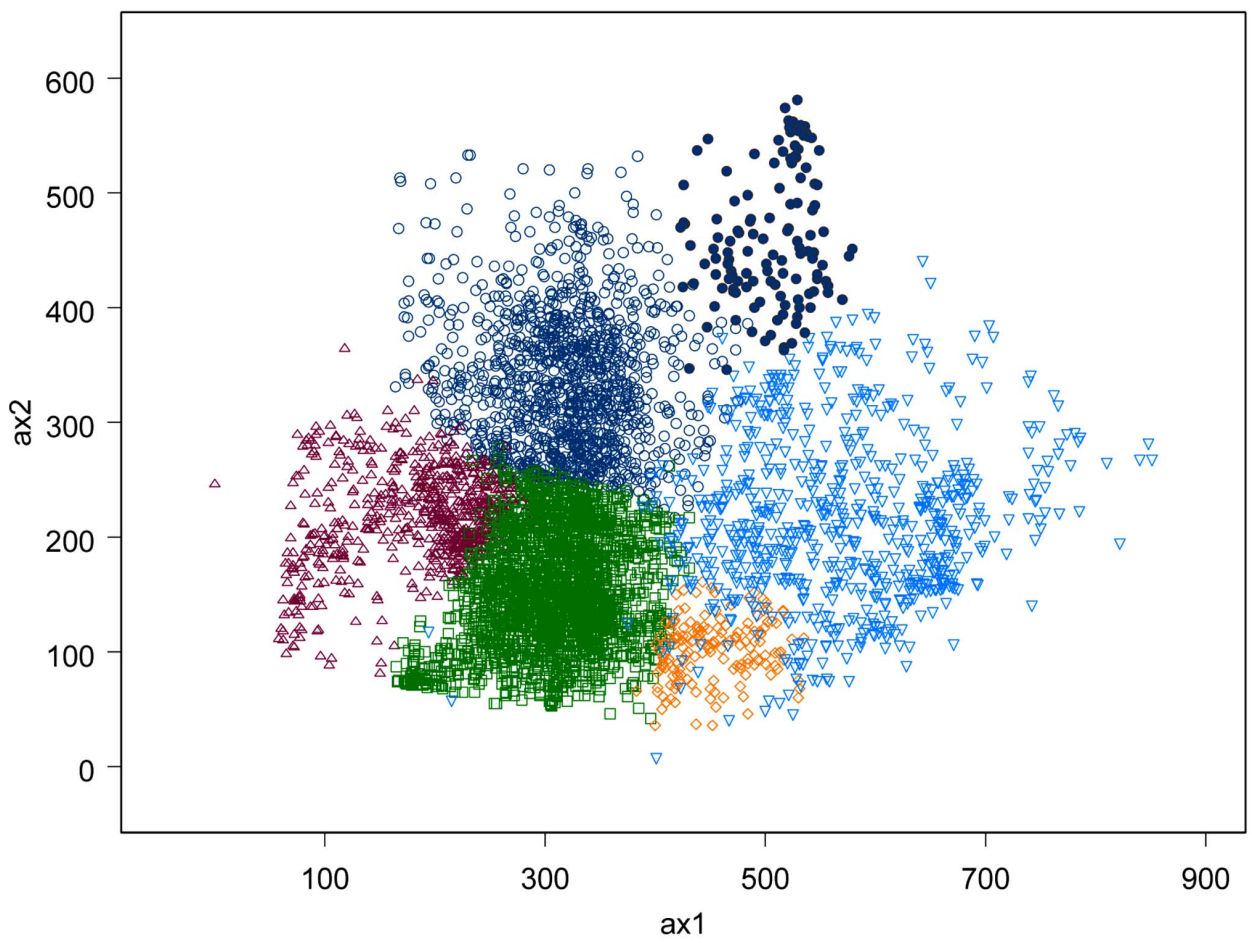

Fig. (2). Projection in ordination space of the 5316 dune plots and the six predicted coastal dune community types according to the supervised classification model. The "grey dune" plots are shown in red triangles, dune grasslands in open blue circles, dry dune heathland in green squares, wet dune heathland in yellow diamonds, nutrient poor dune slack in blue triangles and nutrient rich dune slacks in enclosed blue circles. 
canescens, lichens and bryophytes such as Polytrichum piliferum and Racomitrium spp. to pioneer vegetation in rather wet humid dune slacks with Sphagnum spp., Juncus bulbosus, Drosera intermedia and Rhynchospora fusca. The second axis ranges from dune heathland with Vaccinium uliginosum, Erica tetralix, Juniperus communis and Empetrum nigrum to dune grassland with Tanacetum vulgare, Festuca arundinacea and Lolium perenne and nutrient rich dune slacks with Iris pseudacorus, Peucedanum palustre and Phalaris arundinacea. This floristic gradient, thus, corresponds to a combined gradient in $\mathrm{pH}$ and nutrient availability.

\section{Plant Cover}

The plant cover data were partitioned into the six classified community types, and the cover data of each observed species were fitted to the zero-inflated generalised binomial distribution (equation 1) for each community type. The fitted parameters of the five most typical species for each dune community type (i.e. the species with the highest

Table 2. Estimated Plant Cover of the Dominant Species in each of the Six Coastal Dune Communities: Grey Dune (GD), Dune Grassland (DG), Dry Dune Heathland (DH), Wet Dune Heathland (WH), Nutrient Poor Dune Slacks (PS), Nutrient Rich Dune Slacks (RS). The Three Parameters $(p, q$, and $\delta$ ) are Defined in Equation 1. In the Column Marked $P(\delta=0)$, the Probability for the Test that the Local Distribution of the Plant may be Assumed to be Uncorrelated is Shown. The Regional Estimates of the Mean and Variance of Plant Cover are given in the Last Two Columns. The Estimated Plant Cover of all Observed Plant Species may be found in the Electronic Supplement Table S1

\begin{tabular}{|c|c|c|c|c|c|c|c|}
\hline Species & Community & $p$ & $q$ & $\delta$ & $\mathrm{P}(\delta=0)$ & Mean & Variance \\
\hline Corynephorus canescens & GD & 0.283892 & 0.026848 & 0.459007 & $<0.0001$ & 0.019226 & 0.009367 \\
\hline Cladonia sp. & GD & 0.178628 & 0.031654 & 0.450475 & $<0.0001$ & 0.026 & 0.012353 \\
\hline Dicranum scoparium & GD & 0.274322 & 0.032423 & 0.586703 & $<0.0001$ & 0.023528 & 0.014154 \\
\hline Ammophila arenaria & GD & 0.155502 & 0.091225 & 0.450427 & $<0.0001$ & 0.077039 & 0.035032 \\
\hline Campylopus introflexus & GD & 0.575758 & 0.011913 & 0.762475 & $<0.0001$ & 0.005054 & 0.003916 \\
\hline Galium verum & DG & 0.415473 & 0.002622 & 0.102549 & $<0.0001$ & 0.001533 & 0.000244 \\
\hline Festuca rubra & DG & 0.366762 & 0.007609 & 0.117971 & $<0.0001$ & 0.004818 & 0.000841 \\
\hline Agrostis capillaris & DG & 0.302292 & 0.017513 & 0.334907 & $<0.0001$ & 0.012219 & 0.004584 \\
\hline Rumex acetosella & DG & 0.126074 & 0.00903 & 0.306858 & $<0.0001$ & 0.007892 & 0.002748 \\
\hline Carex arenaria & DG & 0.008596 & 0.121072 & 0.301181 & $<0.0001$ & 0.120032 & 0.036507 \\
\hline Calluna vulgaris & $\mathrm{DH}$ & 0.059539 & 0.257534 & 0.624938 & $<0.0001$ & 0.2422 & 0.120309 \\
\hline Polypodium vulgare & $\mathrm{DH}$ & 0.112125 & 0.020099 & 0.229517 & $<0.0001$ & 0.017845 & 0.004896 \\
\hline Hypnum jutlandicum & $\mathrm{DH}$ & 0.816601 & 0.138755 & 0.499893 & $<0.0001$ & 0.025447 & 0.014524 \\
\hline Vaccinium uliginosum & WH & 0.036364 & 0.439714 & 0.509215 & $<0.0001$ & 0.423724 & 0.134949 \\
\hline Erica tetralix & WH & 0.036364 & 0.279526 & 0.348645 & $<0.0001$ & 0.269362 & 0.078299 \\
\hline Bryopsida & WH & 0.042424 & 0.348531 & 0.55242 & $<0.0001$ & 0.333745 & 0.131127 \\
\hline Pinus mugo & WH & 0.775758 & 0.008157 & 0.202041 & 0.000119 & 0.001829 & 0.000469 \\
\hline Juncus arcticus ssp. balticus & WH & 0.515152 & 0.010738 & 0.670641 & $<0.0001$ & 0.005206 & 0.003589 \\
\hline Molinia caerulea & PS & 0.168813 & 0.251159 & 0.726997 & $<0.0001$ & 0.20876 & 0.125169 \\
\hline Carex nigra & PS & 0.031474 & 0.214855 & 0.55512 & $<0.0001$ & 0.208093 & 0.096647 \\
\hline Sphagnum & PS & 0.224607 & 0.137573 & 0.796641 & $<0.0001$ & 0.106673 & 0.077755 \\
\hline Eriophorum angustifolium & PS & 0.078684 & 0.112468 & 0.482931 & $<0.0001$ & 0.103618 & 0.048302 \\
\hline Carex panicea & PS & 0.127325 & 0.064318 & 0.435544 & $<0.0001$ & 0.056129 & 0.025187 \\
\hline Phragmites australis & RS & 0.036036 & 0.219336 & 0.603668 & $<0.0001$ & 0.211432 & 0.1054 \\
\hline Lycopus europaeus & $\mathrm{RS}$ & 0.09009 & 0.074473 & 0.315419 & $<0.0001$ & 0.067764 & 0.02292 \\
\hline Galium palustre ssp. pal. & $\mathrm{RS}$ & 0.009009 & 0.107097 & 0.476404 & $<0.0001$ & 0.106132 & 0.04835 \\
\hline Lythrum salicaria & RS & 0.108108 & 0.086071 & 0.394811 & $<0.0001$ & 0.076766 & 0.031067 \\
\hline Cirsium palustre & RS & 0.099099 & 0.050589 & 0.333364 & $<0.0001$ & 0.045576 & 0.016456 \\
\hline
\end{tabular}


indicator value, Damgaard et al., 2008) are shown in Table 2 (the fitted parameters of all the species from all the dune community types may be found in the Electronic Supplement Table S1). For most species, the intra-plot correlation was significantly larger than zero, indicating an aggregated spatial distribution of the plant species. There was a significant positive correlation between estimated mean plant cover and the degree of intra-plot correlation $(\mathrm{P}<0.001$ in all dune community types), suggesting that in order for a plant species to be dominant in a dune community, it either has to be large or rely on clonal propagation. The significant positive correlation of plant cover and spatial aggregation in dune community may be compared to tropical forests, where it has been found that the abundance of trees measured by density, i.e. not corrected for the size of individuals, is negatively correlated to a measure of spatial aggregation (Condit et al., 2000).

\section{Diversity}

The calculated diversity measures of the six dune communities are shown in Table 3. In the interpretation of the diversity measures, it is important to note that only the higher plants are determined to species level and that the diversity of mosses and lichens are underrepresented in the measures. The most diverse dune community types are dune grasslands and nutrient poor dune slacks. These community types include many species, and none of the species are particularly dominant (high Simpson diversity). The dry dune heathlands also contain many species, but are dominated by relatively few species (low Simpson diversity and high Gini coefficient). The grey dunes are the most species poor dune community, as far as higher plants, but these communities contain many different mosses and lichens that are underrepresented in this study. The Gini coefficients, i.e. inequalities in plant cover, are not significantly different for grey dunes, dune grasslands and nutrient poor dune slacks.

For none of the dune communities the distribution of plant covers departed significantly from a log-normal distribution (LAC not significantly different from one).

\section{DISCUSSION}

The regional and local distribution of plant covers of all the observed plant species in the different coastal dune communities are summarised by the three parameters in the zero-inflated generalised binomial distribution, and generally, the mean estimates of plant cover were roughly as expected for the different coastal dune communities (Christensen, 1989, Willis, 1989), although there was a surprisingly high cover of Deschampsia flexuosa in many of the investigated coastal dune communities (Nielsen et al., E pub). We expect that the reporting of the cover and the spatial arrangement of each species separately and conditioned on the presence of a specific plant community using hierarchical pin-point data will enable a more fruitful comparison of mosaic plant communities across regional scales relative to comparing estimates by e.g. $\alpha$ - and $\beta$ diversity where a specific spatial sampling design is determined a priori (Magurran, 2004, Jost, 2007, Tuomisto, 2010), which is problematic when the plant communities form mosaic patterns that depend on the physical-chemical properties of the micro-environment.

The different summary statistics of diversity and inequality were also in line with the prior plant ecological expectations of the diversity of the different dune plant communities, where the dune grasslands and the nutrient poor dune slacks, generally, are found to be the most diverse plant communities.

Several ecological processes may lead to the same diversity pattern and therefore it is generally problematic to test ecological hypothesis using diversity patterns and the real use of quantifying diversity patterns arise in the comparison among plant communities of the same habitat type across space or time, e.g. in a ecological monitoring programme. However, lately it has been suggested that lognormally distributed abundance curves indicate a relatively undisturbed ecosystem, in the sense that the plant communities may be assumed to be self-organized and little disturbed by exceptional external factors, is still relatively untested and open for discussion. Although, in a metaanalysis of 23 cases, it was found that that departure from a log-normal distribution of abundance increased with disturbance in 19 cases (Halloy and Barratt, 2007). Here it is important to emphasize that in a coastal dune ecosystem, where the plant species are adapted to recurrent events of wind disturbance, wind disturbance cannot be considered an exceptional external factor. On the contrary, if wind disturbance is prevented, e.g. by reducing the normal grazing pressure and allowing trees to establish on the dunes, then

Table 3. Diversity Measures for the Six Dune Community Types. 95\% Bootstrap Confidence Intervals are given in Parentheses. The Diversity Measures are Calculated from the Estimates of the Mean Plant Cover in Order to Characterise the Regional Diversity of the Different Dune Community Types $(\gamma$ - Diversity)

\begin{tabular}{|c|c|c|c|c|c|c|}
\hline $\begin{array}{c}\text { Diversity } \\
\text { measure }\end{array}$ & Grey dune & Dune grassland & $\begin{array}{c}\text { Dry dune } \\
\text { heathland }\end{array}$ & $\begin{array}{c}\text { Wet dune } \\
\text { heathland }\end{array}$ & $\begin{array}{c}\text { Nutrient poor } \\
\text { dune slack }\end{array}$ & $\begin{array}{c}\text { Nutrient rich } \\
\text { dune slack }\end{array}$ \\
\hline \hline \# species & 117 & 391 & 224 & 65 & 249 & 140 \\
\hline Shannon & $20.9(15.9-27.9)$ & $73.9(55.9-107)$ & $15.7(11.9-24.8)$ & $12.6(9.1-18.1)$ & $46.5(37.9-63.0)$ & $51.2(43.1-63.1)$ \\
\hline Simpson & $13.2(9.0-18.9)$ & $31.7(24.1-61.7)$ & $8.7(5.5-13.5)$ & $8.2(5.1-12.9)$ & $23.3(17.6-33.4)$ & $30.1(23.1-40.8)$ \\
\hline Gini & $0.87(0.82-0.89)$ & $0.83(0.79-0.87)$ & $0.94(0.90-0.95)$ & $0.86(0.79-0.88)$ & $0.84(0.79-0.87)$ & $0.72(0.66-0.76)$ \\
\hline LAC & $0.98(0.89-1.02)$ & $0.98(0.90-1.02)$ & $0.97(0.94-1.03)$ & $1.02(0.91-1.12)$ & $0.99(0.92-1.04)$ & $1.00(0.91-1.07)$ \\
\hline
\end{tabular}


the dune ecosystem may be considered to be influenced by an exceptional external factor, and during the following process of succession, the abundance curves may deviate from a log-normal distribution. Our analyses indicate that the monitored Danish dune habitats are in a relatively undisturbed and self-organized condition. It would be interesting though to investigate temporal trends in species composition in the repeated subset of the monitored dune plots and analyze if the magnitude of trends in different communities co-varies with the static indicators for structure and function developed in this study.

In the present study, it is suggested to measure departure from log-normally distributed abundance curves by a method that uses the properties of the Lorenz curve (Damgaard and Weiner, 2000). This method has the advantage that the direction of the departure is measured, i.e., if LAC $<1$, the inequality in the distribution of plant cover is primarily caused by relatively many rare species, and if $\mathrm{LAC}>1$, the inequality in the distribution of plant cover is primarily caused by a few, very abundant, species (Damgaard and Weiner, 2000). We expect that the added information on the direction of the deviation from the log-normal distribution will be important for interpreting the underlying cause of observed departures from log-normally distributed abundance curves.

\section{SUPPLEMENTARY MATERIAL}

Supplementary material is available on the publishers Web site along with the published article.

\section{REFERENCES}

Béla, T (1995) Comparison of different methods for diversity ordering. Journal of Vegetation Science 6, 283-90.

Christensen, SN (1989) Floristic and vegetational changes in a permanent plot in a Danish coastal dune heath. Annals of Botany Fennici 26, 389-97.

Condit, R, Ashton, PS, Baker, P, Bunyavejchewin, S, Gunatilleke, S, Gunatilleke, N, Hubbell, SP Foster, RB, Itoh, A, LaFrankie, JV, Lee, HS, Losos, E, Manokaran, N, Sukumar, R \& Yamakura, T (2000) Spatial patterns in the distribution of tropical tree species. Science 288, 1414-8

Cordonnier, T, Courbaud, B, \& Franc A (2006) The effect of colonization and competition processes on the relation between disturbance and diversity in plant communities. Journal of Theoretical Biology 243, $1-12$.

Dagum, C (1980) The generation and distribution of income, the Lorenz curve and the Gini ratio. Économie Appliquée 33, 327-67.

Damgaard, C (2008) Modelling pin-point plant cover data along an environmental gradient. Ecological Modelling 214, 404-10.

Damgaard, C (2009) On the distribution of plant abundance data. Ecological Informatics 4, 76-82.

Damgaard, C, Nygaard, B \& Nielsen, KE (2008) Danske kystklitter vegetation og jordbundskemi. Analyser af NOVANA data (2004 2006). Silkeborg, Danmark, Danmarks Miljøundersøgelser, Aarhus Universitet.

Damgaard, C, Weiner, J (2000) Describing inequality in plant size or fecundity. Ecology 81,1139-42.

Doody, JP (1994) The coastal dunes of Europe. Danish dunes - monitoring, management and reseach. Copenhagen, Denmark, Ministry of the Environment, National Forest and Nature Agency.

Dufrene, M \& Legendre, P (1997) Species assemblages and indicator species: the need for a flexible asymmetrical approach. Ecological Monograph 67, 345-66.

EU (1992) Council Directive 92/43/EEC of 21 May 1992 on the conservation of natural habitats and of wild fauna and flora. European Commision.
EUNIS (2008) European Topic Centre on Biological Diversity. Consultation Tool on biogeographical assessments of conservation status for species and habitats reported by Member States according to the provisions of Article 17 of the Habitat Directive

European Commission (2007) Interpretation Manual of European Union Habitats EUR27. Bruxelles, DG Environment. Nature and Biodiversity.

Fredshavn, J (2004) Teknisk anvisning til kortlægning af terrestriske naturtyper. TA N3-1.01. . Kalø, Danmark, Danmarks Mijøundersøgelser.

Gini, C (1912) Variabilitá e mutabilita. In: Pizetti E \& Salvemini T (Eds.) Memorie di metodologia statistica (1955). Rome, Italy, Libreria Eredi Virgilio Veschi.

Gray, JS (1981) Detecting pollution induced changes in communities using the log-normal distribution of individuals among species. Marine Pollution Bulletin 12, 173-6.

Halloy, SRP \& Barratt, BIP (2007) Patterns of abundance and morphology as indicators of ecosystem status: A meta-analysis. Ecological Complexity, 4, 128-47.

Herben, T, During, HJ \& Law, R (2000) Statio-temporal patterns in grassland communities. In: Dieckmann U, Law R \& Metz JAJ (Eds.) The geometry of ecological interactions: Simplifying spatial complexity. Cambridge, Cambridge University Press.

Jost, L (2007) Partitioning diversity into independent alpha and beta components. Ecology 88, 2427-9.

Kent, MG \& Greco CF, Belaoussoff S (1997) Log-normality of biodiversity and abundance in diagnosis and measuring of ecosystemic health: pesticide stress on pollinators on blueberry heaths. Journal of Applied Ecology 34, 1122-36.

Kevan, PG, Greco, CF \& Belaoussoff, S (1997) Log-normality of biodiversity and abundance in diagnosis and measuring of ecosystemic health: pesticide stress on pollinators on blueberry heaths. Journal of Applied Ecology 34, 1122-36.

Leibold, MA, Holyoak, M, Mouquet, N, Amarasekare, P, Chase, JM, Hoopes, MF, Holt, RD, Shurin, JB, Law, R, Tilman, D, Loreau, M \& Gonzalez, A (2004) The metacommunity concept: a framework for multi-scale community ecology. Ecology Letters, 7, 601-13.

Lorenz, MO (1905) Methods for measuring the concentration of wealth. American Statistics Association 9,209-19.

MacArthur, RH \& Wilson, EO (1967) The theory of island biogeography Princeton, Princeton University Press.

Magurran, AE (2004) Measuring biological diversity Malden MA, USA, Blackwell.

McGill, BJ, Etienne, RS, Gray, JS, Alonso, D, Anderson, MJ, Benecha, HK, Dornelas, M, Enquist, BJ, Green, JL, He, F, Hurlbert, AH, Magurran, AE, Marquet, PA, Maurer, BA, Ostling, A, Soykan, CU, Ugland, KI \& White, EP (2007) Species abundance distributions: moving beyond single prediction theories to integration within an ecological framework. Ecology Letters 10,995-1015.

Nielsen, KE, Degn, HJ, Damgaard, C, Bruus, M \& Nygaard, B (In press) A native species with invasive behaviour in coastal dunes: evidence for progressing decay and homogenization of habitat types. Ambio

Pacala, S \& Levin, SA (1997) Biological generated spatial pattern and the coexistence of competing species. In: Tilman, D \& Kareiva, P (Eds.) Spatial ecology. The role of space in population dynamics and interspecific interactions. Princeton, Princeton University Press.

Preston, FW (1948) The commonness, and rarity of species. Ecology 29 254-83.

Rees, M, Condit, R, Crawley, M, Pacala, S, \& Tilman D (2001) Long-term studies of vegetation dynamics. Science 293, 650-5.

Sen, A (1973) On economic inequality Oxford, UK, Clarendon.

Stoll, P \&Weiner, J (2000) A neighbourhood view of interactions among individual plants In: Dieckmann U, Law R \& Metz JAJ (Eds.) The geometry of ecological interactions: Simplifying spatial complexity. Cambridge, Cambridge University Press.

Sugihara, G (1980) Minimal community structure: an explanation of species abundance patterns. American Naturalist 116, 770-87.

Svendsen, LM, van der Bijl, L, Boutrup, S \& Norup, B (2005) NOVANA. National monitoring and assessment programme for the aquatic and terrestrial environments. Programme description - part 2., Silkeborg, Denmark, National Environmental Research Institute.

Tuomisto, H (2010) A diversity of beta diversities: straightening up a concept gone awry. Part 1 . Defining beta diversity as a function of alpha and gamma diversity. Ecography 33, 2-22. 
Veer, MAC \& Kooijman, AM (1997) Nitrogen availability in relation to vegetation changes resulting from grass-encroachment in Dutch dry dunes. Plant and Soil 192, 119-28.

Warming, E (1909) Dansk Plantevakst. 2. Klitterne., København, Danmark, Gyldendalske Boghandel, Nordisk Boghandel.

Weiner, J \& Solbrig, OT (1984) The meaning and measurement of size hierarchies in plant populations. Oecologia 61, 334-6.
Willis, AJ (1989) Coastal sand dunes as biological systems. Proceedings of the Royal Society of Edinburgh 96B, 17-36.

Wittebolle, L, Marzorati, M, Clement, L, Balloi, A, Daffonchio, D, Heylen, K, De Vos, P, Verstraete, W \& Boon, N (2009) Initial community evenness favours functionality under selective stress. Nature 458 , 623-6..

(C) Damgaard et al.; Licensee Bentham Open.

This is an open access article licensed under the terms of the Creative Commons Attribution Non-Commercial License (http://creativecommons.org/ licenses/by-nc/3.0/), which permits unrestricted, non-commercial use, distribution and reproduction in any medium, provided the work is properly cited. 